\title{
Effect of Potassium Sorbate and Ultrasonic Treatment on the Properties of Fish Scale Collagen/Polyvinyl Alcohol Composite Film
}

\author{
Xue Liang ${ }^{1,+}{ }^{\dagger}$, Shiyi Feng ${ }^{1,+}$, Saeed Ahmed ${ }^{1}$, Wen Qin ${ }^{1}$ and Yaowen Liu ${ }^{1,2,3, *}$ \\ College of Food Science, Sichuan Agricultural University, Yaan 625014, China \\ School of Materials Science and Engineering, Southwest Jiaotong University, Chengdu 610031, China \\ 3 California NanoSystems Institute, University of California, Los Angeles, CA 90095, USA \\ * Correspondence: lyw@my.swjtu.edu.cn \\ + These authors contributed equally to the work.
}

Received: 10 June 2019; Accepted: 26 June 2019; Published: 26 June 2019

\begin{abstract}
Composite films containing different amounts of potassium sorbate (KS) were prepared by using fish scale collagen (Col) and polyvinyl alcohol (PVA). Fourier transform infrared spectroscopy (FTIR), light transmittance, mechanical, water vapor transmission rate (WVTR), and the antibacterial properties of the composite films were analyzed. The results showed that the addition of Col significantly reduced the light transmittance of the composite film, but KS had no significant effect on the light transmission. The tensile strength decreased first and then increased with the addition of KS, while the WVTR increased first and then decreased. The composite film exhibited a certain degree of antibacterial properties against E. coli and S. aureus. In addition, we found that ultrasonic treatment reduced the WVTR, and also improved tensile strength and elongation at break of the composite films, but had no significant effect on other properties. The KS/Col/PVA films have the potential to be used as antimicrobial food packaging.
\end{abstract}

Keywords: potassium sorbate; fish scale collagen; polyvinyl alcohol; ultrasonic treatment; composite films; antibacterial activity

\section{Introduction}

At present, safe and non-toxic degradable packaging materials are research hotspots in the field of food packaging, many researchers use natural biomacromolecules to form different films, such as proteins, polysaccharides, lipids, etc. Collagen can be easily obtained from fish scales, and accounts for $50 \%-70 \%$ of the total mass of fish scales. In addition, the macromolecular spiral structure in fish scales has certain thermal stability and tight fiber structure, which makes the collagen show better toughness, strength and biodegradability. However, the collagen film shows brittleness and solubility in water, which limited its wider application [1]. Polyvinyl alcohol (PVA) is a degradable macromolecular plastic material with good optical properties, high tensile strength and good barrier properties. In addition, PVA has a good application prospect in the field of food packaging [2-4]. Due to the defects of fish scale collagen $(\mathrm{Col})$, many papers reported to composite with PVA as the composite film-forming substrate for packaging materials.

Potassium sorbate (KS) is an unsaturated fatty acid salt of sorbic acid, which can be quickly decomposed by the metabolic system. The concentration of KS has no effect on the flavor of the food and has a good inhibitory effect on mold, yeast, and aerobic bacteria. It is one of the most commonly used antimicrobial agents against fungi, yeast and some bacteria $[5,6]$. KS has been widely studied in food preservation packaging. Kowalczyk et al. used carboxymethyl cellulose as the substrate emulsion 
and added KS to the antifungal effect of the composite coated on apricot. It was found that coating with KS is very effective approach against Botrytis cinerea and brown rot [7]. It can effectively delay the softening of the apricot and efficiently extend its shelf life. Sousa et al. also found the biodegradable films containing KS could guarantee the microbiological safety of fresh lasagna pastas and avoid the excessive consumption of food additives [8]. Gunaydin et al. added KS as an antifungal agent to the hydroxypropyl methylcellulose-beeswax composite film and studied its effect on the physical and chemical properties of the plums during cold storage. Potassium acid, sodium methylparaben, and sodium hydroxybenzoate composite coated films all showed good preservation effects and did not adversely affect the sensory flavor of the plums and appearance of the fruits [9]. Türe et al. prepared a wheat gluten-resistant antibacterial film containing KS. They found that the composite films showed excellent antimicrobial activity against Aspergillus niger [10]. Pranoto et al. fabricated different composite films by adding garlic oil, KS and nisin as antibacterial agents. Adding KS significantly reduced the tensile strength of the composite films, but KS reduced the compactness of the film structure. Because the interaction between the amino group and the carboxyl group of the hydrophilic group in the film inhibits the release of KS, the antibacterial effect of the composite films was weaker than others [11]. Studies have shown that KS can improve the physicochemical, and antibacterial properties of the packaging films $[7,8]$. Currently, KS is not particularly extensive studied.

In this study, the fish Col and PVA were used as film-forming substrates, and added KS as an antibacterial agent. Morphology, tensile strength, WVTR, and antibacterial properties of the composite films were discussed in relation to their ingredient concentration. In addition, sonication treatment was used to improve some certain properties of the composite film.

\section{Results and Discussion}

\subsection{SEM}

In the present study, the impact of KS addition on material morphology was evaluated by SEM (Figure 1). It can be seen that as the concentration of KS increases, it has a significant effect on morphology of the films. The surface of all samples showed dense, uniform and good film forming properties. The roughness the film gradually increased, and obvious agglomeration occurs especially in $12 \%$ KS-Col-PVA film. As the the concentration of KS is too high, it causes uneven dispersion.
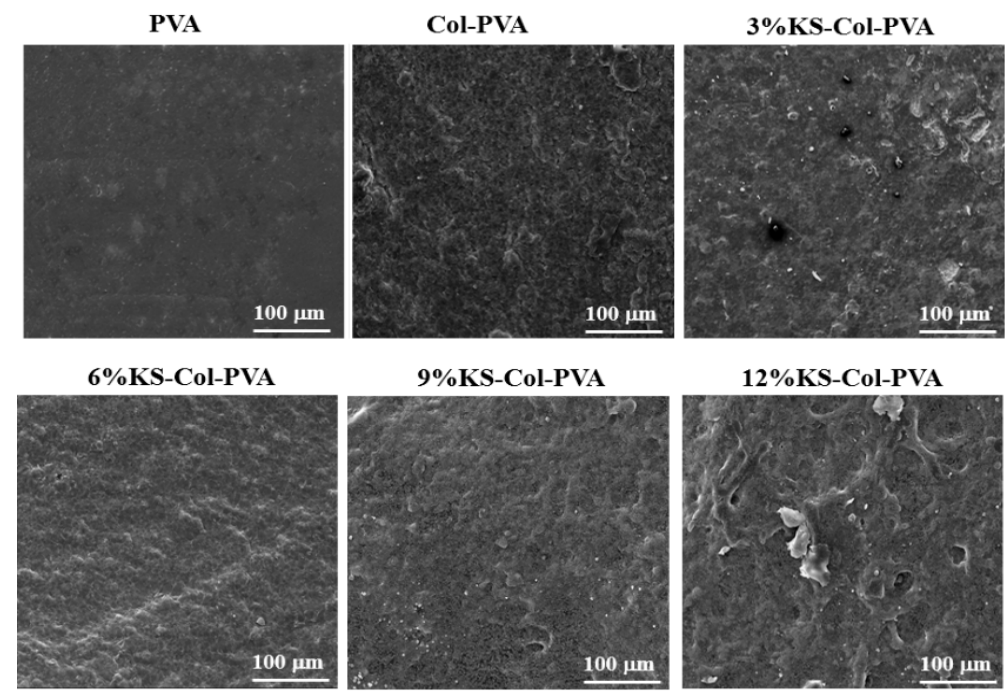

Figure 1. SEM micrographs of the PVA, Col-PVA, and KS-Col-PVA films. 


\subsection{Transparency and Color of the Films}

Figure 2 shows the solution with different content of KS. It can be seen that the PVA and Col solution are colorless and transparent. The color of the solution is not obvious when different concentrations of KS were added.

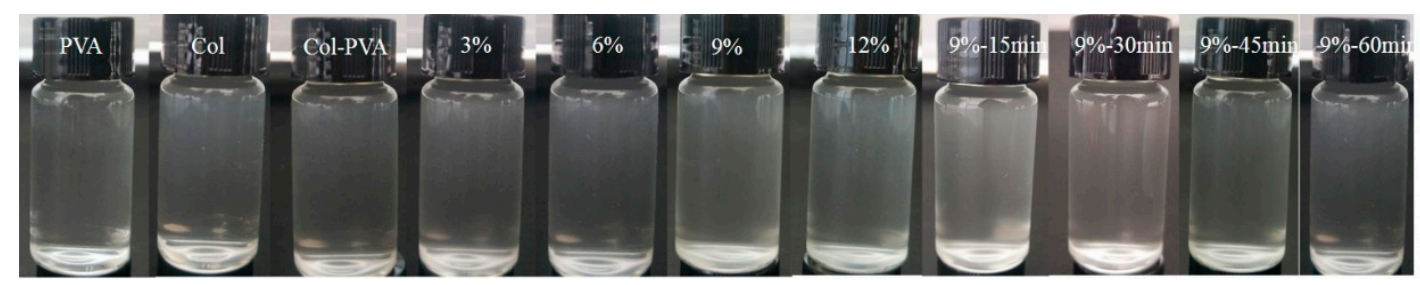

Figure 2. Photograph of composite film solution.

It can be seen from the Figure 3 that the 12\% KS-Col-PVA film form more fragments on the surface as SEM image, while other groups have good film-forming properties, and the appearance of the film is uniform and transparent. After adding KS, the surface of the film is rougher than PVA film.

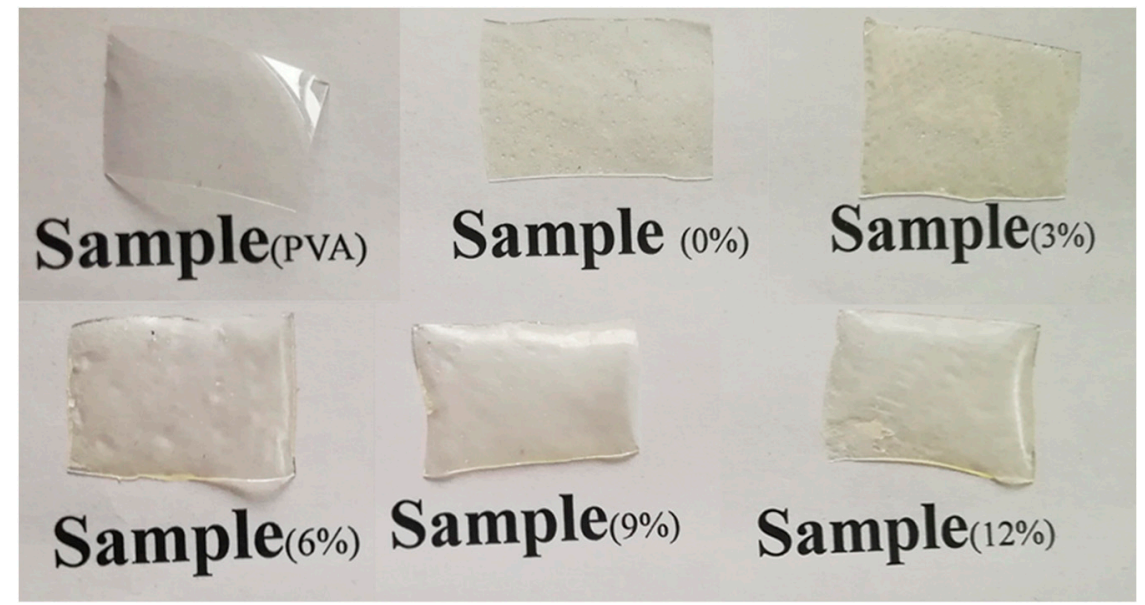

Figure 3. Photograph of PVA and different content KS composite films.

The transparency and color of the packaging material is an important indicator reflecting the appearance of the packaged product. Table 1 shows that the addition of Col caused a significant decrease in the transparency of the composite film $(p<0.05)$, while the addition of KS had a certain effect on the transparency of the composite film, and the difference was not significant $(p>0.05)$. Lopez et al. also proved that the addition of KS has little effect on the light transmission of the composite film [12], so perhaps the addition of collagen reduced the transparency of the composite film. When the content of KS was low, protein and PVA molecules could complete the interaction very well. However, when the content was too high, self-phase gathers and forms crystals will occur to block the passage of light. Table 1 shows the color parameters $\Delta \mathrm{E}$ of composite films. The addition of KS decreased the $\mathrm{L}^{*}$ in the films, leading to a decrease in the transparency of the films. In addition, the presence of KS produced a significant increase in $\Delta \mathrm{E}$. The $\Delta \mathrm{E}$ value of films with Col and KS resulted in a significantly higher value than the control. The $\Delta \mathrm{E}$ increase was attributed to the increased $\mathrm{b}^{*}$, indicating that active films have more yellow than the control samples due to sorbate oxidative browning [13]. Sousa et al. also mentioned in his research, that this yellowing of the films could be explained by the partial degradation of sorbate by high temperatures employed in the extrusion process, which probably favored the Maillard reaction between the carboxyl group of KS and the matrix of the film [14]. Chevalier et al. also demonstrated that the yellowing could be attributed to the Ti oxidative degradation of KS by cleavage of the double bonds, leading to aldehydes and ketones [15]. 
Table 1. Effect of KS concentration on average thickness (AT), moisture content (MC), tensile strength (TS), elongation at break (EAB) and transparency $(\mathrm{T})$ of different composite films.

\begin{tabular}{|c|c|c|c|c|c|c|c|c|c|}
\hline \multirow{2}{*}{ Sample } & \multirow{2}{*}{ AT (mm) } & \multirow{2}{*}{ MC (\%) } & \multirow{2}{*}{ TS (MPa) } & \multirow{2}{*}{ ЕAB (\%) } & \multirow{2}{*}{$\mathrm{T}(\%)$} & \multicolumn{4}{|c|}{ Color } \\
\hline & & & & & & $L^{*}$ & $a^{*}$ & $b^{*}$ & $\Delta \mathrm{E}$ \\
\hline PVA & $60.33 \pm 2.52^{\mathrm{a}}$ & $5.9 \pm 0.19^{\mathrm{a}}$ & $17.4 \pm 0.9^{\mathrm{a}}$ & $14.35 \pm 1.11^{\mathrm{a}}$ & $90.87 \pm 0.50^{\mathrm{a}}$ & $85.28 \pm 0.16^{\mathrm{a}}$ & $2.29 \pm 0.17^{\mathrm{a}}$ & $3.74 \pm 1.32^{\mathrm{a}}$ & $1.61 \pm 0.16^{\mathrm{a}}$ \\
\hline Col-PVA & $57.88 \pm 3.79^{b}$ & $16.1 \pm 2.10^{\mathrm{b}}$ & $10.9 \pm 1.2^{\mathrm{b}}$ & $4.35 \pm 0.58^{\mathrm{b}}$ & $85.73 \pm 2.29^{b}$ & $83.38 \pm 0.39^{b}$ & $2.26 \pm 0.15^{\mathrm{a}}$ & $7.39 \pm 2.61^{b}$ & $2.50 \pm 0.16^{b}$ \\
\hline $6 \% \mathrm{KS}$ & $64.33 \pm 4.16^{c}$ & $17.9 \pm 2.22^{b}$ & $4.8 \pm 0.6^{\mathrm{d}}$ & $5.43 \pm 0.55^{\mathrm{c}}$ & $87.57 \pm 0.95^{\mathrm{b}}$ & $82.52 \pm 1.40^{\mathrm{b}}$ & $2.32 \pm 0.19^{a}$ & $9.68 \pm 3.42^{b}$ & $3.00 \pm 0.78^{c}$ \\
\hline $9 \% \mathrm{KS}$ & $60.00 \pm 2.31^{\mathrm{a}}$ & $15.3 \pm 1.78^{\mathrm{b}}$ & $3.3 \pm 0.5^{\mathrm{d}}$ & $5.77 \pm 0.51^{\mathrm{c}}$ & $87.80 \pm 1.21^{b}$ & $84.08 \pm 0.19^{\mathrm{a}}$ & $2.26 \pm 0.15^{\mathrm{a}}$ & $11.71 \pm 4.14^{\mathrm{c}}$ & $2.78 \pm 0.12^{b}$ \\
\hline $12 \% \mathrm{KS}$ & $57.33 \pm 3.06^{\mathrm{b}}$ & $15.2 \pm 1.46^{\mathrm{b}}$ & $3.5 \pm 0.8^{\mathrm{d}}$ & $5.49 \pm 0.39^{c}$ & $88.93 \pm 0.45^{\mathrm{a}}$ & $84.64 \pm 0.10^{\mathrm{a}}$ & $2.28+0.17^{\mathrm{a}}$ & $13.15 \pm 4.65^{c}$ & $2.98 \pm 0.03^{c}$ \\
\hline
\end{tabular}

\subsection{Mechanical Properties}

The average thickness, tensile strength (TS) and elongation at break (EAB) of the films are presented in Table 1. The TS of pure PVA is $(17.4 \pm 0.9) \mathrm{MPa}$, and the addition of Col significantly reduces the TS of the composite film. When the amount of addition reached $9 \%$, the TS of the composite film reached a minimum value of $(3.3 \pm 0.5) \mathrm{MPa}$, due to the addition of KS destroying some molecules. The interaction caused the TS of the composite film to decrease, but when the amount of addition was $12 \%$, the TS increased to $(3.5 \pm 0.8)$ MPa because of the small molecular substance. When the polar group carboxyl group, hydroxyl group in the KS molecule interact with the amino group and the carboxyl group in the protein molecule to form a physical crosslink, the crosslink between the molecules is tighter, which increases the compactness of the film and reduces the density of the film. Many researchers also reported that different composite films exhibited similar properties in TS after the addition of KS [10,11].

It can be seen in Table 1 that the EAB of the pure PVA film is the best, $(14.35 \pm 1.11) \%$. After addition of the Col, the EAB of the composite films decreased significantly $(p<0.05)$, from $(14.35 \pm 1.11) \%$ to $(4.35 \pm 0.58) \%$. With the increase in the amount of KS, an increase in EAB, from $(4.35 \pm 0.58) \%$ (Col-PVA) to $(5.77 \pm 0.51) \%$ (9\% KS-Col-PVA), occurred. This is due to the interactions between the chains of antimicrobial agents, which penetrate with ease into the film matrix. Consequently, there is greater mobility between the chains, producing films with lower TS and greater flexibility [16,17].

\subsection{FTIR Analysis}

Figure 4 shows that the main functional groups of Col are as follows: $3338 \mathrm{~cm}^{-1}$ is the amide $\mathrm{A}$ band (-NH stretching vibration), $2930 \mathrm{~cm}^{-1}$ is the amide B band (-CH stretching vibration), and $1649 \mathrm{~cm}^{-1}$ is the amide I band ( $\mathrm{C}=\mathrm{O}$ stretching vibration and $-\mathrm{NH}$ in-plane bending vibration), $1453 \mathrm{~cm}^{-1}$ is the amide II band (the absorption peak of the $\mathrm{CH}_{2}$ - and -COO- bonds), and $1238 \mathrm{~cm}^{-1}$ is the amide III band (the stretching vibration of the -NH bond), $1655 \mathrm{~cm}^{-1}$ is the stretching vibration of the $\mathrm{C}=\mathrm{O}$ bond (amide I band) [18]; the characteristic functional group absorption peak of KS is mainly located at the stretching vibration of $\mathrm{C}=\mathrm{O}$ bond at $1649 \mathrm{~cm}^{-1}$. For the characteristic functional group of PVA, the absorption peaks are mainly the stretching vibration absorption peak of the -OH bond near $3300-3400 \mathrm{~cm}^{-1}$, the $-\mathrm{CH}$ stretching vibration peak near $2900 \mathrm{~cm}^{-1}$, and the three peaks of $1750-1500 \mathrm{~cm}^{-1}$ from the high wave number to the low wave number, $\mathrm{C}=\mathrm{O}$ stretching vibration, -OH deformation vibration, and - $\mathrm{NH}$ deformation vibration. C-O bending vibration from about $1090 \mathrm{~cm}^{-1}$ [19]. It can be seen that after the addition of KS, the peak shape of $3330-3400 \mathrm{~cm}^{-1}, 1536 \mathrm{~cm}^{-1}$, and $1023 \mathrm{~cm}^{-1}$ become higher, and had significant changes. Perhaps the increase in the addition of $\mathrm{KS}$ caused the increase of $-\mathrm{OH}$ radicals in the films. At the same time, it lead to an increase in the absorption peak at the stretching vibration of the $\mathrm{C}=\mathrm{O}$ bond. In the spectrum of PVA-Col-KS film, a change in the amide I band at $1649 \mathrm{~cm}^{-1}$ appears clearly. It is sharper, with the increase of KS incorporated indicating some interaction between a group of PVA [11]. 


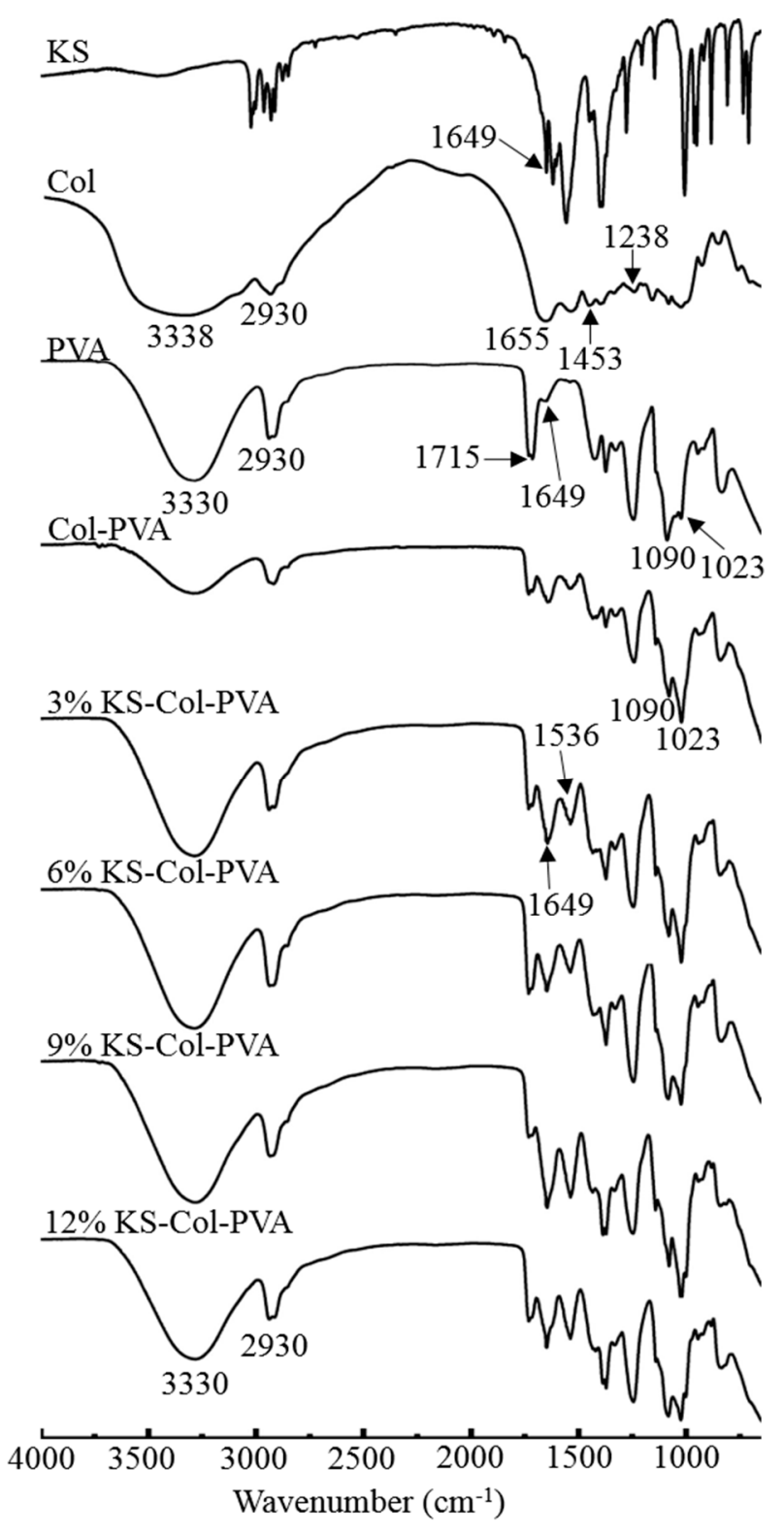

Figure 4. FTIR spectra of the different composite films.

\subsection{WVTR}

Figure 5 shows that the addition of Col and KS significantly increased the WVTR of the composite films, because the substrate of the film is PVA and Col, and both are rich in hydrophilic groups. In addition, KS is also highly hygroscopic, resulting in a gradual increase in the WVTR of the composite films. Shen et al. also showed a change consistency, and explained that the presence of KS interacts with the molecules of the substrate, changing the network structure in the composite film, thereby affecting the water barrier properties of the composite film [20]. When the amount of KS reached $9 \%$, the WVTR of the composite films reached a maximum of $2.04 \times 10^{-12} \mathrm{~g} \cdot \mathrm{cm} /\left(\mathrm{cm}^{2} \cdot \mathrm{s} \cdot P a\right)$. When added to $12 \%$, the WVTR of the composite films reduced to $1.74 \times 10^{-12} \mathrm{~g} \cdot \mathrm{cm} /\left(\mathrm{cm}^{2} \cdot \mathrm{s} \cdot \mathrm{Pa}\right)$, perhaps due to the excessive hydrogen bond between the carboxyl group in the KS molecule and the amino group in the protein molecule. The combination increased the compactness of the film, making it difficult for water molecules to diffuse in the film, resulting in a decrease. Many previous studies found that the addition of KS significantly improved the structure of the composite film, affecting the mechanical properties and water barrier properties of the composite films [10,21,22]. 


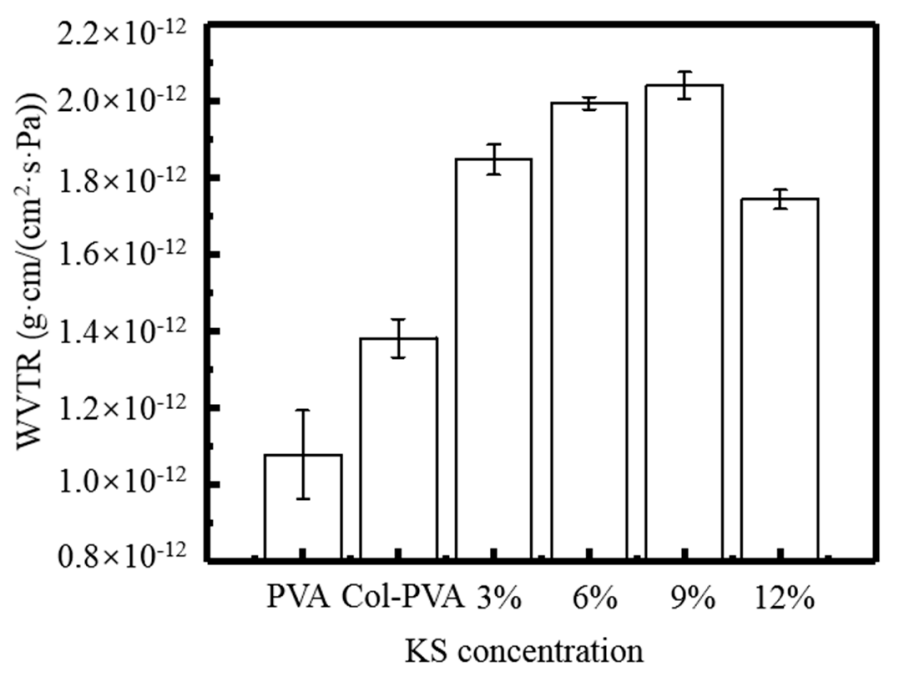

Figure 5. WVTR at different KS content of KS-Col-PVA composite film.

\subsection{Antibacterial Testing}

In order to investigate the antibacterial effect of KS as an antibacterial agent for the composite films, typical food pathogenic bacteria E. coli and S. aureus were used as representative bacteria. PVA film has almost no antibacterial properties, and the addition of the Col enhances the antibacterial property of the composite film to a certain extent, but it is still less than $50 \%$. KS enhanced the antibacterial property of the composite film, but the enhancement effect was not obvious. When the KS content is $12 \%$, the antibacterial rate of the composite film against $E$. coli is $69.64 \%$, and the $S$. aureus is $58.59 \%$. Shen et al. also showed that when the content of KS was less than $10 \%$, there was no obvious inhibitory effect on E. coli., due to the hydrogen bond interaction between hydroxyl groups of starch and carboxyl groups of KS, which reduced the release of KS around the diaphragm [20]. In addition, it was also found that the inhibitory effect on $S$. aureus was very weak in the whole experimental concentration range of KS.

As can be seen from Figure 6, the antibacterial effect of the composite film on E. coli is superior to that of $S$. aureus. As the cell wall lipid content of Gram-negative bacteria is higher, KS molecules are easier to pass, and the cell wall of Gram-positive bacteria contains a large amount of peptidoglycan, which is not easy to pass, thus causing different antibacterial rates against the two bacteria. The antibacterial mechanism of KS could enter the cell through the cell film of the microorganism, causing the $\mathrm{pH}$ value in the cell to decrease, changing the film permeability of the cell film or reducing the proton kinetics to destroy the substrate transport, thereby inhibiting the basic metabolic reaction of the cell [20]. In addition, when KS enters the cell, it can bind to the sulfhydryl group in the microbial enzyme system, thereby destroying many enzyme systems and achieving consistent microbial growth and reproduction, thereby exerting antibacterial and antiseptic effects. 


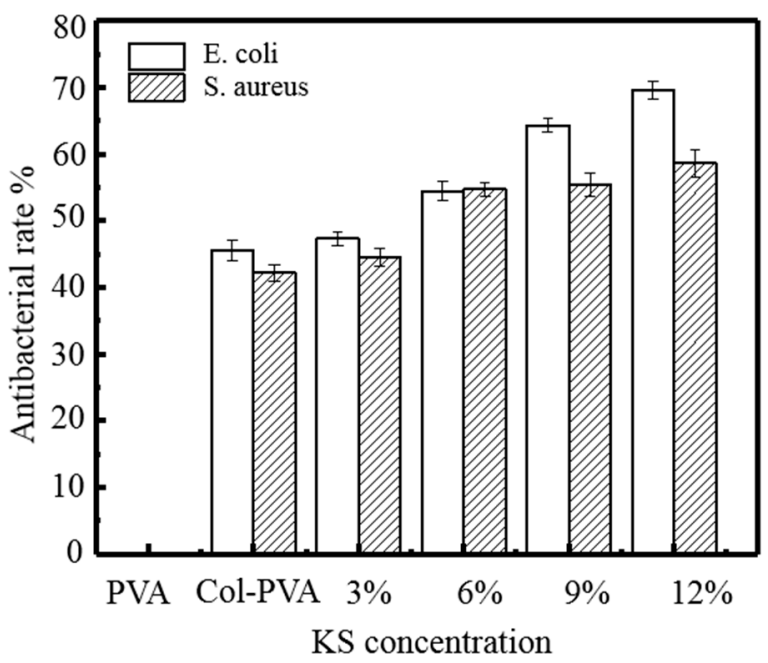

Figure 6. Antibacterial rate of E. coli and S. aureus at different KS content of KS-Col-PVA composite film.

\subsection{Effect of Ultrasonic Treatment Film Forming Solution on the Performance of the Composite Film}

In order to study the effect of ultrasonic treatment of composite films, $9 \%$ KS-Col-PVA was selected for ultrasonic treatment at different times $(0,15,30,45,60 \mathrm{~min})$, and the ultrasonic power was $120 \mathrm{~W}$, $50 \mathrm{kHz}$. After ultrasonic treated, the film was formed on the Teflon plate, and various performance changes were tested.

Table 2 reflects the changes in film properties after ultrasonic treated. It can be seen that with the increase of ultrasonic time, the transparency of the composite films gradually improved. When the ultrasonic time was 30-45 $\mathrm{min}$, the transparency of the composite film reached the minimum value $(86.83 \% \pm 0.40 \%)$. When the ultrasonic time was $45 \mathrm{~min}$, the TS of the composite film changed significantly, reaching the maximum value of $(5.9 \pm 0.10) \mathrm{MPa}$. With the extension of time, the TS and EAB showed a decrease. When the ultrasonic time was $60 \mathrm{~min}$, the TS was $(3.4 \pm 0.21) \mathrm{MPa}$ and the EAB was $(13.02 \pm 0.88) \%$. Ultrasound treatment had no significant effect on the appearance of film, so it was no longer to discuss here. Table 2 also shows that the color of the film changed slightly. With the increase of ultrasonic time, the $\Delta \mathrm{E}$ value increased first and then decreased. This is due to the more uniform dispersion of KS in the film by ultrasound, which increased the contact between KS and the outside world, thus aggravating sorbate oxidative browning.

Table 2. Properties of the film prepared using ultrasound treated $9 \%$ KS-Col-PVA composite film (AT: average thickness, MC: moisture content, TS: tensile strength, EAB: elongation at break, T: transparency).

\begin{tabular}{|c|c|c|c|c|c|c|c|c|c|}
\hline \multirow{2}{*}{ Sample. } & \multirow{2}{*}{ AT (mm) } & \multirow{2}{*}{ MC (\%) } & \multirow{2}{*}{ TS (MPa) } & \multirow{2}{*}{ ЕАВ (\%) } & \multirow{2}{*}{$\mathrm{T}(\%)$} & \multicolumn{3}{|c|}{ Color } & \multirow[b]{2}{*}{$\Delta \mathbf{E}$} \\
\hline & & & & & & $\mathbf{L}^{*}$ & $a^{*}$ & $\mathbf{b}^{*}$ & \\
\hline $9 \%-0$ & $60.00 \pm 2.31^{\mathrm{a}}$ & $15.3 \pm 1.78^{\mathrm{a}}$ & $3.3 \pm 0.5^{\mathrm{d}}$ & $5.77 \pm 0.51^{\mathrm{c}}$ & $87.80 \pm 1.21^{b}$ & $84.08 \pm 0.19^{a}$ & $2.26 \pm 0.15^{a}$ & $11.71 \pm 4.14^{\mathrm{a}}$ & $2.78 \pm 0.12^{\mathrm{a}}$ \\
\hline $9 \%-15$ & $57.07 \pm 3.61^{\mathrm{b}}$ & $16.7 \pm 1.32^{\mathrm{a}}$ & $4.5 \pm 0.33^{\mathrm{b}}$ & $14.48 \pm 0.92^{\mathrm{a}}$ & $88.03 \pm 0.25^{\mathrm{a}}$ & $83.89 \pm 0.10^{\mathrm{a}}$ & $2.20 \pm 0.10^{\mathrm{b}}$ & $15.66 \pm 5.54^{\mathrm{b}}$ & $3.12 \pm 0.29^{b}$ \\
\hline $9 \%-45$ & $59.33 \pm 2.65^{\mathrm{a}}$ & $13.6 \pm 0.98^{b}$ & $5.9 \pm 0.10^{\mathrm{a}}$ & $13.13 \pm 0.94^{\mathrm{a}}$ & $86.83 \pm 0.40^{\mathrm{a}}$ & $82.80 \pm 1.11^{b}$ & $2.24 \pm 0.19^{\mathrm{a}}$ & $18.53 \pm 6.55^{c}$ & $2.78 \pm 0.08^{\mathrm{a}}$ \\
\hline $9 \%-60$ & $57.41 \pm 3.46^{\mathrm{b}}$ & $14.8 \pm 0.87^{\mathrm{a}}$ & $3.4 \pm 0.21^{\mathrm{a}}$ & $13.02 \pm 0.88^{\mathrm{a}}$ & $86.85 \pm 0.21^{\mathrm{a}}$ & $84.25 \pm 0.14^{\mathrm{a}}$ & $2.20 \pm 0.10^{\mathrm{b}}$ & $21.11 \pm 6.46^{\mathrm{d}}$ & $2.93 \pm 0.13^{\mathrm{a}}$ \\
\hline
\end{tabular}

Figure 7 shows that the WVTR decreases slightly with ultrasonic time. When time reached $60 \mathrm{~min}$, the lowest WVPR of composite films was $1.02 \times 10^{-12} \mathrm{~g} \cdot \mathrm{cm} /\left(\mathrm{cm}^{2} \cdot \mathrm{s} \cdot P a\right)$. From Figure 8, it can be seen that: 1) the area of the peak at $2930 \mathrm{~cm}^{-1}$ increased, 2) the absorption intensity of the peak at $1649 \mathrm{~cm}^{-1}$ decreased, and 3) the area of the peak at $1024 \mathrm{~cm}^{-1}$ decreased significantly after ultrasonic treatment. The performances of composite films were improved after ultrasonic treatment for a certain 
time, as the cavitation and super mixing effects of ultrasonic treatment break some chemical bonds in molecules, reduce the size of particles, expose many reaction groups, and facilitate the interaction between molecules. Keeping molecules at a high temperature and pressure makes the interaction between the molecules more rapid and orderly, enhancing the network structure of the film, and thus increasing the transparency of the film [23,24]. Moreover, the ultrasonic treated made the molecules of various substances fully stretched, the TS, EAB, and WVTR of the composite films were significantly improved. When the ultrasonic time increased to $60 \mathrm{~min}$, the transparency of the composite film did not change significantly, but the TS and EAB decreased significantly, and the WVTR increased significantly. This is due to a large number of chemical bonds in the film breaking, making it difficult to form a dense network structure. At the same time, the disordered interaction makes it difficult to form an orderly structure among the molecules, thus weakening the performance of all aspects [21]. Figure 9 shows the antibacterial rate of the composite film increased after ultrasonic treatment, but the effect was small $(p>0.05)$. When the ultrasonic time was $45 \mathrm{~min}$, the maximum antibacterial rate against $E$. coli was $74.11 \%$. When the ultrasonic time was $60 \mathrm{~min}$, the maximum antibacterial rate against $S$. aureus was $64.84 \%$. During the ultrasonic treatment, the molecular chain of each substance in the composite film was gradually broken and exposed, resulting in an increase in the amount of contact with the bacterial cells, thereby causing a slight increase in the antibacterial effect.

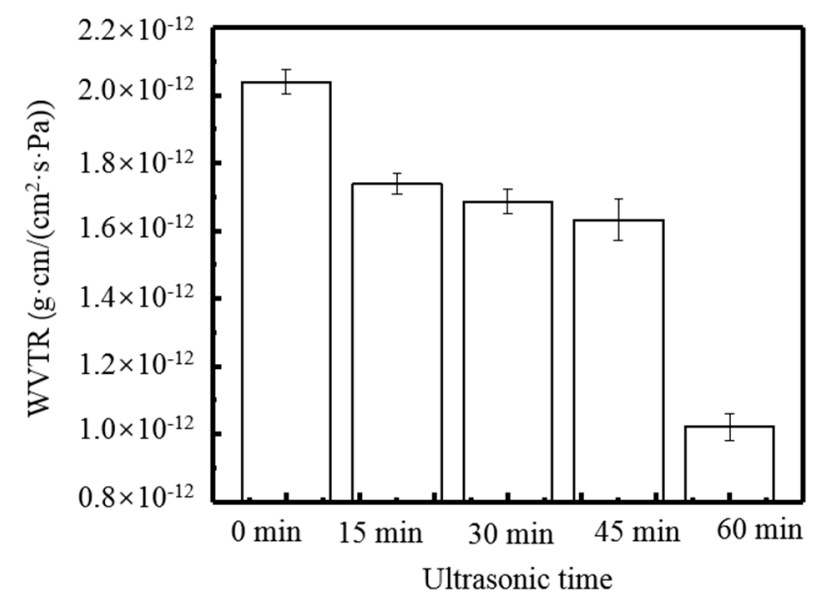

Figure 7. Effect of time of ultrasound treatment of film solution on WVTR. 


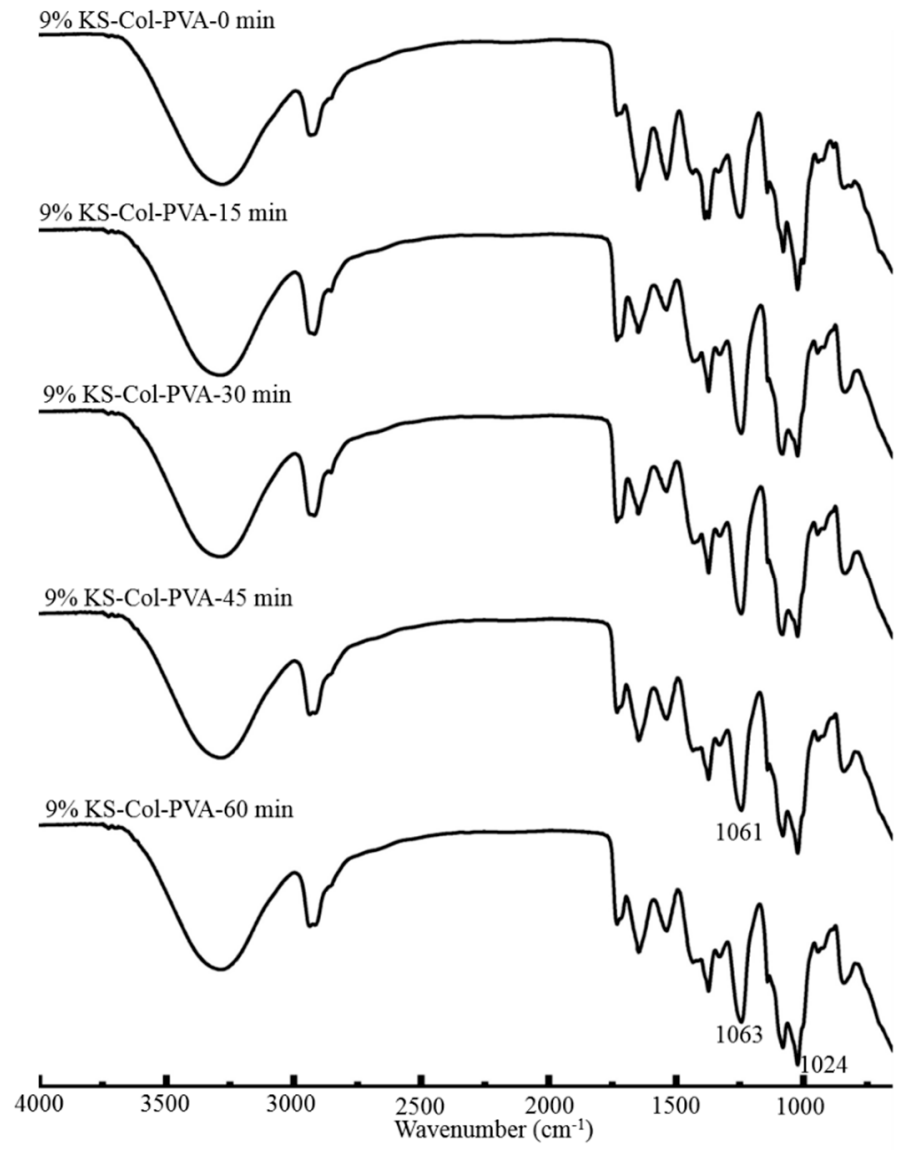

Figure 8. Effect of time of ultrasound treatment of the $9 \%$ KS-Col-PVA composite films on FTIR.

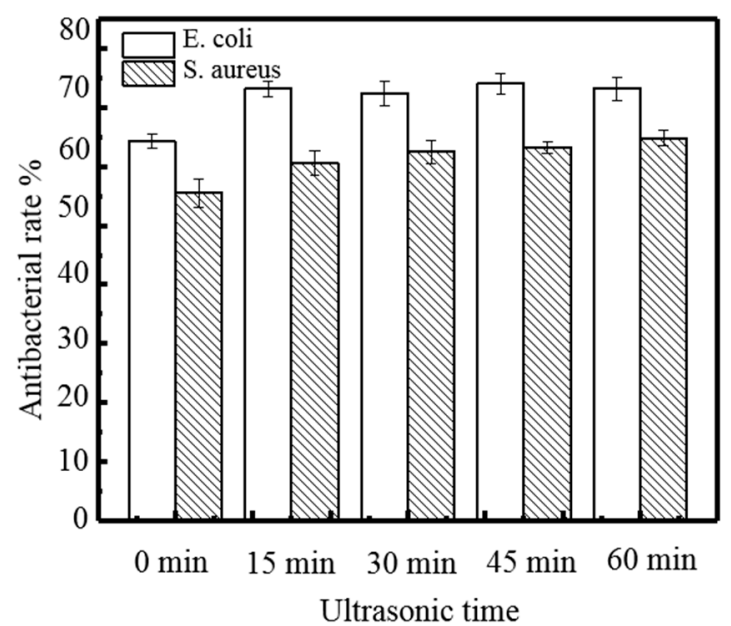

Figure 9. Effect of ultrasound times effect on the antibacterial rate of the film.

\section{Materials and Methods}

\subsection{Materials}

KS and fish Col were obtained from Sigma Aldrich (St Louis, MO, USA). PVA (Mw $=7.6 \mathrm{kDa}$, $\mathrm{Mw} / \mathrm{Mn}=1.32$ ) was purchased from Shenzhen Esun Industrial Co., Ltd. (Shenzhen, China). All other chemicals and solvents were grade or higher purity and purchased from Chengdu Kelong Reagent Co. (Chengdu, China) unless otherwise indicated. 


\subsection{Preparation of KS-Col-PVA Composite Films}

$8 \mathrm{~g}$ of $\mathrm{Col}$ powder was dissolved in $92 \mathrm{~g}$ distilled water, and magnetically stirred at $35^{\circ} \mathrm{C}$ water bath for $30 \mathrm{~min}$ to obtain a uniform Col solution. Then, $8 \mathrm{~g}$ PVA powder was added into $90 \mathrm{~g}$ of distilled water and stirred to obtain a bubble-free homogeneous $8 \%(\mathrm{w} / \mathrm{w})$ PVA solution. $30 \mathrm{~g}$ Col solution and $30 \mathrm{~g}$ of PVA solution were mixed and magnetically stirred for $60 \mathrm{~min}$ [19]. KS powder was weighed and added again to the above Col/PVA mixture solution. Glycerol $(2 \mathrm{~g} / 60 \mathrm{~g})$ was used as a plasticizer. Then, $100 \mathrm{~g}$ of solution was poured into square plates $(20 \mathrm{~cm} \times 20 \mathrm{~cm})$ and dried at $45{ }^{\circ} \mathrm{C}$. Table 3 shows the composition of the different films prepared in this study. All groups have good film-forming properties except the Col solution. Therefore, the Col sample is no longer used and analyzed in subsequent tests.

Table 3. Composition of different composite solutions.

\begin{tabular}{ccccc}
\hline Sample & KS $(g)$ & Col (g) & PVA (g) & Gly (g) \\
\hline Pure-PVA & 0 & 0 & 4.8 & 2 \\
Col & 0 & 4.8 & 0 & 2 \\
Col-PVA & 0 & 2.4 & 2.4 & 2 \\
3\%KS-Col-PVA & 0.162 & 2.4 & 2.4 & 2 \\
6\%KS-Col-PVA & 0.324 & 2.4 & 2.4 & 2 \\
9\%KS-Col-PVA & 0.486 & 2.4 & 2.4 & 2 \\
12\%KS-Col-PVA & 0.648 & 2.4 & 2.4 & 2 \\
\hline
\end{tabular}

\subsection{Scanning Electronic Microscope (SEM)}

Micro-structural analysis of composite films was performed using a scanning electron microscope (ZEISS-Supra 55, Jena, Germany). All of composite films were bonded to a conductive carbon tape, coated with $\mathrm{Au}$, and determined by using an accelerating voltage of $20 \mathrm{kV}$ [25].

\subsection{Transparency and Color of Composite Films}

All films were cut into rectangular pieces $(10 \mathrm{~mm} \times 30 \mathrm{~mm})$ and placed on the internal side of a spectrophotometer cell. Transparency of films was measured by a spectrophotometer (Model V-530, Jasco International, Tokyo, Japan) at $600 \mathrm{~nm}$. Five replicates of films were tested. The transparency (\%) was calculated as the percentual relationship between the light intensity with the specimen in the beam and the light intensity with no specimen in the beam [26]. Color of films were determined with a colorimeter (Minolta chromameter CR-200) using the CIELAB color parameters. L, a, and b values were averaged from nine readings across for each sample on a white background: $L=83.96 \pm 0.06$; $\mathrm{a}=2.05 \pm 0.09 ; \mathrm{b}=1.99 \pm 0.07$. The total color difference $(\Delta \mathrm{E})$ was calculated according to Equation $(1)$ :

$$
\Delta \mathrm{E}=\left(\Delta \mathrm{L}^{*}\right)^{2}+\left(\Delta \mathrm{a}^{*}\right)^{2}+\left(\Delta \mathrm{b}^{*}\right)^{2}
$$

where $\Delta \mathrm{L}^{*}, \Delta \mathrm{a}^{*}$ and $\Delta \mathrm{b}^{*}$ are the differentials between a sample color parameter and the color parameters of formulation without $\mathrm{Col}$ and without KS used as standard [27].

\subsection{Mechanical Properties}

The mechanical properties of films were obtained at $25^{\circ} \mathrm{C}$ The tensile strength (TS) and elongation at break (EAB) of the films were measured by a universal testing machine (UTM, Instron 5583, Instron, Boston, USA). The films were cut into $60 \times 10 \mathrm{~mm}$ strips, the samples were placed between the tensile grips allowing a grip separation distance of $40 \mathrm{~mm}$ with a tensile rate of $10 \mathrm{~mm} / \mathrm{min}$. The following properties were calculated from the stress-deformation curves by the following Equations (2) and (3):

$$
\mathrm{TS}=\mathrm{F}_{\mathrm{MAX}} /(\mathrm{A} \times \mathrm{d})
$$




$$
\% \mathrm{E}=100 \times \mathrm{L} / \mathrm{L}_{0}
$$

where: $F_{M A X}=$ the pick force at break $(\mathrm{N}), A=$ the film thickness $(\mathrm{mm}), \mathrm{d}=$ the films width $(\mathrm{mm})$, $\mathrm{L}=$ the films length at break $(\mathrm{mm}), \mathrm{L}_{0}=$ the initial film length $(\mathrm{mm})$ [28].

\subsection{Fourier Transform Infrared (FTIR) Analysis}

The interaction among Col, PVA and KS was investigated by a FITR spectroscopy at $25^{\circ} \mathrm{C}$ All the samples were recorded on a FT-IR NICOLET 10 spectrophotometer (FT-IR NICOLET 10). The FTIR analysis was performed on the powder state of $\mathrm{Col}$ and KS, mixed with KBr powder and palletized. A transmittance mode was used to obtain the FTIR absorption spectrum. The FTIR spectra analysis was performed in the mean infrared region with a wavenumber range of $4000-650 \mathrm{~cm}^{-1}$ by averaging 32 scans and spectral resolution of $4 \mathrm{~cm}^{-1}$. The experiment was performed twice to verify that the spectra was consistent between individual samples.

\subsection{Water Vapor Transmission Rate and Water Solubility}

The water vapor transmission rate (WVTR) of all the films were evaluated through the procedure described in a previous study of Liang et al. [29]. Briefly, the mouth of a cup containing dry calcium chloride was sealed with the film at $25{ }^{\circ} \mathrm{C}$ under $75 \%$ relative humidity. The cups were weighed periodically to obtain the mass of moisture transferred through the film into the cup. The WVTR was determined once the weight stopped changing with time and calculated by dividing the slope of the line by the exposed film area on the cup according to Equation (4):

$$
\mathrm{WVTR}=\Delta \mathrm{m} /(\Delta \mathrm{t} \times \mathrm{A})
$$

where $\Delta \mathrm{m} / \Delta \mathrm{t}$ is the slope $(\mathrm{g} / \mathrm{s}), \mathrm{A}$ is the area of the exposed film surface $\left(\mathrm{m}^{2}\right)$.

The water solubility of KS/Col/PVA films were determined after $24 \mathrm{~h}$ of distilled water immersion. Disc-shaped films (approximately $2 \mathrm{~cm}$ in diameter) were immersed in distilled water $50 \mathrm{~mL}$ ) and kept under mechanical stirring by using a shaker at room temperature. After $24 \mathrm{~h}$, samples were dried at $105^{\circ} \mathrm{C}$ for $24 \mathrm{~h}$ to determine the final dry mass. The solubility, expressed in terms of dissolved dry mass, was determined according to Equation (5):

$$
\mathrm{S}=\left(\left|\mathrm{m}_{0}-\mathrm{m}_{\mathrm{f}}\right|\right) / \mathrm{m}_{0} \times 100 \%
$$

where $\mathrm{S}$ is the water solubility $\left(\mathrm{g} / 100 \mathrm{~g}\right.$ film); $\mathrm{m}_{0}$ is the dry mass of the sample $(\mathrm{g})$, and $\mathrm{m}_{\mathrm{f}}$ is the final mass of the sample after immersion for $24 \mathrm{~h}(\mathrm{~g})$.

\subsection{Antibacterial Tests}

For the antibacterial tests, S. aureus and E. coli were selected as Gram-positive and Gram-negative bacteria, respectively. Samples from performed in dynamic shake flask method according to ASTM E2149-10. Bacteria was transferred from stock culture to slant culture medium and then transferred into $5 \mathrm{~mL}$ nutritious broth (NB) tube. The tubes were incubated at $37^{\circ} \mathrm{C}$ for $24 \mathrm{~h}$ and then $1 \mathrm{~mL}$ was pipetted into $50 \mathrm{~mL}$ NB flasks. The films were cut into pieces and $0.3 \mathrm{~g}$ films were added into the flasks and incubated at $37^{\circ} \mathrm{C}$ for $24 \mathrm{~h}$. The 10 -fold serial dilutions were made by using phosphate-buffered saline $9 \mathrm{~mL} /$ tube and $1 \mathrm{~mL}$ of each flask pipetted into a dilution tube and diluted continuously to nine tubes. Then, $0.1 \mathrm{~mL}$ of bacteria suspension with dilution factor $10^{6}-10^{8}$ was taken into sterilized plates containing $10 \mathrm{~mL}$ NB by pipette and plates were incubated at $37^{\circ} \mathrm{C}$ for $24 \mathrm{~h}$. All experiments were conducted in triplicate. The colony forming units (CFU) of bacteria were counted, and the antibacterial rate (R) were calculated via Equations (6) and (7), respectively [30]:

$$
\mathrm{CFU} / \mathrm{mL}=(\text { content of colony } \times \text { Dilution factor }) /(\text { volume of dilution }(0.1 \mathrm{~mL}))
$$




$$
\text { Antibacterial ratio }(\%)=(\mathrm{A}-\mathrm{B}) \times 100 / \mathrm{A} \text {. }
$$

where $\mathrm{A}$ is the $\mathrm{CFU}$ of blank sample and $\mathrm{B}$ is the CFU of antibacterial samples.

\subsection{Statistical Analysis}

One-way analysis of the variance (ANOVA) was performed using Statgraphics Plus for Windows 5.1 (Manugistics Corp., Rockville, MD, USA). Fisher's least significant difference (LSD) was used at the $95 \%$ confidence level.

\section{Conclusions}

The composite films were prepared by using Col and PVA as the film-forming substrate and KS as the antibacterial agent, and its performance was changed by ultrasonic treatment. The results showed that the addition of $\mathrm{Col}$ significantly reduced the light transmittance of the composite film. The ultrasonic treatment improved the transparency and reduced the WVTR of the composite film when ultrasound time reached $45 \mathrm{~min}$. The KS/Col/PVA films have the potential to be used as antimicrobial food packaging.

Author Contributions: X.L. and S.F. developed the original idea and the protocol, abstracted and analyzed data, X.L. wrote the manuscript, Y.L. is the guarantor. S.A. and W.Q. contributed to the development of the protocol, abstracted data, and prepared the manuscript.

Funding: This work was supported by China Scholarship Council, Sichuan Science and Technology Program (2018RZ0034), and Natural Science Fund of Education Department of Sichuan Province (16ZB0044 and 035Z1373).

Conflicts of Interest: The authors declare no conflict of interest.

\section{References}

1. Bernardini, R.D.; Harnedy, P.; Bolton, D.; Kerry, J.; O’Neill, E.; Mullen, A.M.; Hayes, M. Antioxidant and antimicrobial peptidic hydrolysates from muscle protein sources and by-products. Food Chem. 2011, 124, 1296-1307. [CrossRef]

2. Bonilla, J.; Fortunati, E.; Atarés, L.; Chiralt, A.; Kenny, J.M. Physical, structural and antimicrobial properties of poly vinyl alcohol-chitosan biodegradable films. Food Hydrocoll. 2014, 35, 463-470. [CrossRef]

3. Liu, B.; Xu, H.; Zhao, H.; Liu, W.; Zhao, L.; Li, Y. Preparation and characterization of intelligent starch/PVA films for simultaneous colorimetric indication and antimicrobial activity for food packaging applications. Carbohydr. Polym. 2017, 157, 842-849. [CrossRef] [PubMed]

4. Liu, Y.; Wang, S.; Lan, W. Fabrication of antibacterial chitosan-PVA blended film using electrospray technique for food packaging applications. Int. J. Biol. Macromol. 2018, 107, 848-854. [CrossRef] [PubMed]

5. Uz, M.; Altınkaya, S.A. Development of mono and multilayer antimicrobial food packaging materials for controlled release of potassium sorbate. LWT-Food Sci. Technol. 2011, 44, 2302-2309. [CrossRef]

6. Alzate, P.; Miramont, S.; Flores, S.; Gerschenson, L. Effect of the potassium sorbate and carvacrol addition on the properties and antimicrobial activity of tapioca starch - hydroxypropyl methylcellulose edible films. Starch-Starke 2016, 69. [CrossRef]

7. Kowalczyk, D.; Kordowska-Wiater, M.; Złotek, U.; Skrzypek, T. Antifungal resistance and physicochemical attributes of apricots coated with potassium sorbate-added carboxymethyl cellulose-based emulsion. Int. J. Food Sci. Tech. 2018, 53, 728-734. [CrossRef]

8. Sousa, G.M.; Yamashita, F.; Soares Júnior, M.S. Application of biodegradable films made from rice flour, poly(butylene adipate-co-terphthalate), glycerol and potassium sorbate in the preservation of fresh food pastas. LWT-Food Sci. Technol. 2016, 65, 39-45. [CrossRef]

9. Gunaydin, S.; Karaca, H.; Palou, L.; de la Fuente, B.; Pérez-Gago, M.B. Effect of hydroxypropyl Methylcellulose-Beeswax composite edible coatings formulated with or without antifungal agents on physicochemical properties of plums during cold storage. J. Food Quality 2017, 2017, 1-9. [CrossRef]

10. Türe, H.; Gällstedt, M.; Hedenqvist, M.S. Antimicrobial compression-moulded wheat gluten films containing potassium sorbate. Food Res. Int. 2012, 45, 109-115. [CrossRef] 
11. Pranoto, Y.; Rakshit, S.K.; Salokhe, V.M. Enhancing antimicrobial activity of chitosan films by incorporating garlic oil, potassium sorbate and nisin. LWT-Food Sci. Technol. 2005, 38, 859-865. [CrossRef]

12. Lopez, O.V.; Giannuzzi, L.; Zaritzky, N.E.; Garcia, M.A. Potassium sorbate controlled release from corn starch films. Mater. Sci. Eng. C Mater. Biol. Appl. 2013, 33, 1583-1591.

13. Barzegar, H.; Azizi, M.H.; Barzegar, M.; Hamidi-Esfahani, Z. Effect of potassium sorbate on antimicrobial and physical properties of starch-clay nanocomposite films. Carbohydr. Polym. 2014, 110, 26-31. [CrossRef] [PubMed]

14. Sousa, G.M.; Soares Junior, M.S.; Yamashita, F. Active biodegradable films produced with blends of rice flour and poly(butylene adipate co-terephthalate): Effect of potassium sorbate on film characteristics. Mater. Sci. Eng. C Mater. Biol. Appl. 2013, 33, 3153-3159. [CrossRef] [PubMed]

15. Chevalier, E.; Chaabani, A.; Assezat, G.; Prochazka, F.; Oulahal, N. Casein/wax blend extrusion for production of edible films as carriers of potassium sorbate-A comparative study of waxes and potassium sorbate effect. Food Packaging Shelf. 2018, 16, 41-50. [CrossRef]

16. Remedio, L.N.; Silva dos Santos, J.W.; Vieira Maciel, V.B.; Yoshida, C.M.P.; Aparecida de Carvalho, R. Characterization of active chitosan films as a vehicle of potassium sorbate or nisin antimicrobial agents. Food Hydrocoll. 2019, 87, 830-838. [CrossRef]

17. Sayanjali, S.; Ghanbarzadeh, B.; Ghiassifar, S. Evaluation of antimicrobial and physical properties of edible film based on carboxymethyl cellulose containing potassium sorbate on some mycotoxigenic Aspergillus species in fresh pistachios. LWT-Food Sci. Technol. 2011, 44, 1133-1138. [CrossRef]

18. Shi, D.; Liu, F.; Yu, Z.; Chang, B.; Goff, H.D.; Zhong, F. Effect of aging treatment on the physicochemical properties of collagen films. Food Hydrocoll. 2019, 87, 436-447. [CrossRef]

19. Kozlowska, J.; Kaczmarkiewicz, A. Collagen matrices containing poly(vinyl alcohol) microcapsules with retinyl palmitate - Structure, stability, mechanical and swelling properties. Polym. Degrad. Stabil. 2019, 161, 108-113. [CrossRef]

20. Shen, X.L.; Wu, J.M.; Chen, Y.; Zhao, G. Antimicrobial and physical properties of sweet potato starch films incorporated with potassium sorbate or chitosan. Food Hydrocoll. 2010, 24, 285-290. [CrossRef]

21. Basch, C.Y.; Jagus, R.J.; Flores, S.K. Physical and antimicrobial properties of tapioca starch-HPMC edible films incorporated with Nisin and/or potassium sorbate. Food Bioprocess Tech. 2012, 6, 2419-2428. [CrossRef]

22. Muangrat, R.; Nuankham, C. Production of flour film from waste flour during noodle production and its application for preservation of fresh strawberries. CyTA-J. Food 2018, 16, 525-536. [CrossRef]

23. Cheng, W.; Chen, J.; Liu, D.; Ye, X.; Ke, F. Impact of ultrasonic treatment on properties of starch film-forming dispersion and the resulting films. Carbohyd. Polym. 2010, 81, 707-711. [CrossRef]

24. Liu, Y.; Wang, S.; Lan, W.; Qin, W. Development of ultrasound treated polyvinyl alcohol/tea polyphenol composite films and their physicochemical properties. Ultrason. Sonochem. 2019, 51, 386-394. [CrossRef]

25. Gao, W.; Dong, H.; Hou, H.; Zhang, H. Effects of clays with various hydrophilicities on properties of starch-clay nanocomposites by film blowing. Carbohyd. Polym. 2012, 88, 321-328. [CrossRef]

26. Pérez, L.M.; Soazo, M.d.V.; Balagué, C.E.; Rubiolo, A.C.; Verdini, R.A. Effect of pH on the effectiveness of whey protein/glycerol edible films containing potassium sorbate to control non-O157 shiga toxin-producing Escherichia coli in ready-to-eat foods. Food Control 2014, 37, 298-304. [CrossRef]

27. Flores, S.; Famá, L.; Rojas, A.M.; Goyanes, S.; Gerschenson, L. Physical properties of tapioca-starch edible films: Influence of filmmaking and potassium sorbate. Food Res. Int. 2007, 40, 257-265. [CrossRef]

28. Soukoulis, C.; Singh, P.; Macnaughtan, W.; Parmenter, C.; Fisk, I.D. Compositional and physicochemical factors governing the viability of Lactobacillus rhamnosus GG embedded in starch-protein based edible films. Food Hydrocoll. 2016, 52, 876-887. [CrossRef] [PubMed] 
29. Liang, T.; Sun, G.; Cao, L.; Li, J.; Wang, L. Rheological behavior of film-forming solutions and film properties from Artemisia sphaerocephala Krasch. gum and purple onion peel extract. Food Hydrocoll. 2018, 82, 124-134. [CrossRef]

30. Threepopnatkul, P.; Wongnarat, C.; Intolo, W.; Suato, S.; Kulsetthanchalee, C. Effect of TiO2 and ZnO on thin film properties of PET/PBS blend for food packaging applications. Energy Procedia 2014, 56, 102-111. [CrossRef]

Sample Availability: Samples of the compounds are not available from the authors.

(C) 2019 by the authors. Licensee MDPI, Basel, Switzerland. This article is an open access article distributed under the terms and conditions of the Creative Commons Attribution (CC BY) license (http://creativecommons.org/licenses/by/4.0/). 